\title{
ON-BOARD AIRCRAFT OXYGEN GENERATING SYSTEM ${ }^{*}$
}

by

R. J. Kiraly and A. D. Babinsky

TRW Mechanical Products Division Cleveland, Ohio

and

P. D. Quattrone

NASA, Ames Research Center Moffett Field, California
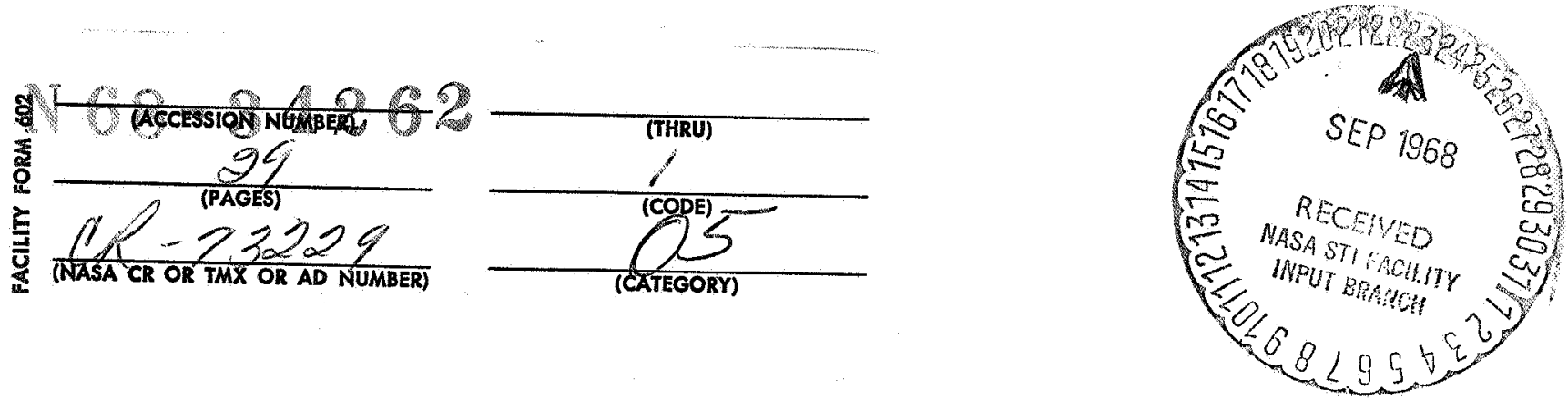

*This work is being supported under NASA Contract NAS2-4444, NASA CR-73229 

INTRODUCTION

The currently used stored liquid oxygen system which supplies breathing oxygen to aviators is costly to the Government from both manpower and ground support standpoints $(1)^{*}$. Due to the remote and limited warfare presently encountered, military attention has been focused on minimizing ground support requirements and thereby establishing new "Bare Bases" to support a variety of tactical missions. This concept has led to the long-range goal of completely eliminating the LOX ground support equipment by replacing the current LOX systems with on-board electrochemical oxygen generators. These units will require a very minimum of ground support equipment and maintenance. Two schemes for accomplishing this are under consideration: 1) provision of oxygen through the electrolysis of water and 2) the separation of oxygen from air through the use of an electrochemica1 ce11, or concentrator (2).

Each has its own particular advantages and disadvantages. It appears that both could be applied in the future, dependent on the type of aircraft, its mission, and the logical extension of equipment used.

The ideal oxygen supply system will consist of either of the electrochemical generators and a minimum amount of process control equipment. To compete with and eventually replace current LOX systems, the total hardware must be of generally the same weight and volume as the current operation LoX units. To accomplish this, it becomes necessary to add a rebreather loop to the oxygen generating equipment. In this loop, the oxygen normally exhaled overboard by the aviator is conserved by removing the carbon dioxide, moisture and odor. With this equipment, the demand placed upon the oxygen generator is merely that of

\footnotetext{
* Numbers in parentheses designate References at end of paper.
} 
providing the aviator's metabolic needs plus the oxygen vented in the rebreather loop nitrogen elimination process (3).

The need for this combination of equipment is readily seen when comparing current military specifications for an aviator's oxygen requirements (employing overboard exhalation) with the flow rate that might be expected from an electrochemical source, but with a rebreather included. This is shown in Table 1.

At sea level, when the pilot is breathing 100 percent oxygen, a mask-equipped aviator without a rebreather requires twenty-three times the oxygen needed by the aviator with a rebreather. As shown in Table 1, the situation becomes more acute when the aviator wears a pressure suit. In addition, wi thout a rebreather, the power required to generate oxygen with current electrochemical techniques becomes excessive. The previously mentioned alkaline electrolyte oxygen concentrator and electrolysis cell consume 100 and 250 watts, respectively, for each 0.1 lb $0_{2} /$ hr generated (4).

These figures indicate that nearly $4 \mathrm{kw}$ would be needed at sea level to supply oxygen to an aviator equipped with a pressure suit and helmet but without a rebreather. By coupling the rebreather circuit to the electrochemical hardware, however, the power requirement becomes reasonable (100 watts/aviator, minimum), and it is projected that this arrangement will occupy approximately the same volume and possess the same weight as its present-day cryogenic counterpart.

\section{NAOS PROGRAM}

Under Contract No. NAS2-4444, TRW, in conjunction with NASA Ames, is developing an aircraft oxygen generating system. 0xygen generated by water electrolysis is fed into the rebreather loop which provides for nitrogen elimination, water removal, and carbon dioxide removal. The carbon dioxide removal is accomplished by an electrochemical carbon dioxide removal device developed by TRW. 


\section{TABLE I}

Aviator's Oxygen Requirements (100\% 0xygen)

No Rebreather (5)

Pressure Suit \&

Mask-Equipped

Aviator
Helmet-Equipped

Aviator

With Rebreather

\begin{tabular}{lcccc} 
Cabin Altitude, ft & $\begin{array}{c}35,000 \& \\
\text { above }\end{array}$ & $\begin{array}{c}\text { Sea } \\
\text { Level }\end{array}$ & $\begin{array}{c}\text { Sea } \\
\text { Level }\end{array}$ & $\begin{array}{c}\text { All } \\
\text { Altitudes }\end{array}$ \\
\hline
\end{tabular}

Flow Rate, 70F, dry

$\begin{array}{lcccc}\text { liter/minute } & 2.3 & 13.1 & 22.2 & 0.57 \\ \text { cubic feet/hour } & 4.9 & 27.8 & 47.0 & 1.21 \\ \text { pound/hour } & 0.4 & 2.3 & 3.9 & 0.10\end{array}$


The electrolysis module incorporates static water feed. In this method, liquid water is fed to the module from a water reservoir. As the water in the potassium hydroxide electrolyte is electrolyzed, its vapor pressure decreases to a value below that in the water feed compartment. This vapor pressure gradient causes a vapor flow from the feed membrane through the hydrogen gas cavity and into the cell electrolyte.

The carbon dioxide concentrator is an electrochemical cell using potassium carbonate as the electrolyte. At the cathode, the reaction of oxygen and water forms hydroxyl ions which act as a "getter" of carbon dioxide. Any carbon dioxide which passes over the electrolyte, now rich in hydroxyl ions, reacts to form carbonate ions. (This reaction is the same as that of the first stage cathode of the carbonation cell (6) studied under NASA Contract NAS3-7638.) At the opposite electrode (anode) the reaction of hydrogen and hydroxyl ions to form water causes the concentration of hydroxyl ions in the electrolyte to decrease. This shifts the equilibrium such that carbon dioxide is given off, completing the transfer of carbon dioxide from the oxygen compartment to the hydrogen compartment.

Major program tasks are: 1) system design, 2) static feed water electrolysis subsystem development, 3) TRW carbon dioxide concentrator development, 4) power conversion and conditioning component development, 5) accessory component design, 6) breadboard system development, 7) electrochemical component life testing and, 8) breadboard system modification for flight testing. The developed components will be integrated into a full-scale laboratory breadboard system. After satisfactory demonstration of the system and its control modes, the breadboard system will be refigured for aircraft flight tests. 


\section{SYSTEM DESIGN}

DESIGN CRITERIA - The design objectives for NAOS are to obtain a safe, reliable system of low weight and size which would eliminate the need for ground support facilities and minimize the time and effort for maintenance. Studies at TRW prior to this program have shown that a system using the electrolysis of water to generate breathing oxygen and an electrochemical device to remove the carbon dioxide from a closed breathing system can successfully meet these objectives. The only periodic servicing required is to refill a water reservoir between flights. The system, being a closed loop, requires the generation of oxygen at a rate equal to that metabolically consumed by the user plus an amount lost due to nitrogen venting, carbon dioxide transfer, and system leakage at the aviator's mask.

The system design specifications are based upon the physiological requirements of a pilot. The breathing loop design requirements are outlined in Table 2 which also shows the basis for the requirements. These requirements are for this first phase program only, and will be revised and expanded in the later phases of the NAOS development; for example, Item 2 in Table 2 will probably be changed to a design rate of near $0.2 \mathrm{lb} / \mathrm{hr}$ to account for the continuous venting of the loop which is required to denitrogenate the pilot. Another requirement that can easily be changed is the ten-hour operating duration which can be extended by making the water reservoir proportionately larger.

Table 3 lists the design goals for a fully developed NAOS prototype. It is intended to use aircraft requirements for flight profile, space availability and services on board as a design guide. Although these requirements and specifications have not been detailed as yet, this information is not critical to the first phase efforts on this program. Some assumptions were therefore made in 


\section{TABLE 2}

Breathing Loop Design Requirements

Requirement

1. Pilot's oxygen consumption $0.10 \mathrm{lb} / \mathrm{hr}$

2. Electrolysis cell oxygen flow rate $0.15 \mathrm{lbs} / \mathrm{hr}$

3. Pilot's respiratory minute volume 0.5 CFM (14 liters/min)

4. Peak instantaneous respi ratory flow rate $-1.6 \mathrm{CFM}$

5. Pilot's tidal volume - 30 to $230 \mathrm{in}^{3}$ (0.5 to 3.81 iters)

6. Temperature of breathing oxygen to pilot $-60^{\circ} \mathrm{F}$ to $90^{\circ} \mathrm{F}\left(70^{\circ} \mathrm{F}-80^{\circ} \mathrm{F}\right.$ preferable)

7. Relative humidity of breathing oxygen to pilot - $50 \%$ maximum

8. Breathing loop absolute pressure levels - 3 psia to 15 psia

9. $\mathrm{CO}_{2}$ concentration in breathing oxygen to pilot - $0.5 \%$ by volume maximum at one atmosphere $13.8 \mathrm{~mm} \mathrm{Hg}$ vapor pressure maximum)

10. $\mathrm{CO}_{2}$ production by pilot $-0.10 \mathrm{lb} / \mathrm{hr}$

11. Operating duration - 10 hours
Bas is For Requi rement

Based on data for light work typical of piloting aircraft

$\mathrm{Pilot}$ 's consumption plus 0.05 $\mathrm{lb} / \mathrm{hr}$ for $\mathrm{CO}_{2}$ concentrator consumption

Typical for light work, also actual measurements on pilots

Assumes sinusoidal respiratory flow

Based on tests, varies with individuals

Comfort

Comfort

Sea level to physiological minimum safe pressure

Well under safe maximum

Metabolically consistant with oxygen consumption

Typical oxygen capacity of existing systems 


\section{TABLE 3}

Oxygen System Design Goals

(First NAOS Prototype)

Oxygen Generating Capacity

Oxygen Purity

Oxygen Supply Pressure

Oxygen Flow Rate to Pilot, average

Oxygen Temperature to $\mathrm{Pilot}$

Peak Respiratory Flow Rate

Oxygen Relative Humidity

System Operating Time

Turn-Around Time

Sys tem Volume

Sys tem Weight

System Power

Rebreather Loop Pressure
$0.20 \mathrm{lb} / \mathrm{hr}$

$99.5 \%$

65 psig

0.5 CFM

$60^{\circ} \mathrm{F}$ to $90^{\circ} \mathrm{F}$

1.6 CFM

$50 \%$ maximum

10 hours ( $+25 \%$ reserve)

5 minutes - water refill

$<1 \mathrm{ft}^{3}$

$\leq 50 \quad$ ib

$<700$ watts

Aircraft cabin pressure plus specified pressure breathing schedule 
the design of the system. These pertain to the availability of electrical power, compressed air for operation of the counter-lung and liquid coolants for heat exchange. Also, as shown in Table 3, system volume is to be minimized but no critical dimensions have been established for packaging.

INITIAL SYSTEM DESIGN - The initial system design is based upon the criteria outlined in Table 2. Figure 1 shows the components required and their arrangement. A blower is used to circulate breathing oxygen through the carbon dioxide concentrator which removes the carbon dioxide from the circulating flow and transfers it to the hydrogen stream on the opposite side of the concentrator cell. Parametric testing of single cell carbon dioxide concentrators has demonstrated good performance independent of oxygen flow rate. This results in the possibility that the blower, check valve, and recirculating loop may not be necessary in the system. This is because it does not appear that the convective transfer of carbon dioxide from the oxygen steam to the electrode is significant resistance compared to the overall resistance of transfer of carbon dioxide from the oxygen to the hydrogen gas streams in the concentrator. At present it is planned to retain the blower and recirculating loop in the system until testing of the carbon dioxide concentrator module indicates that the blower is not required. In this event the system would be simpler, with exhalation flow going directly through the concentrator and back to the aviator.

The pilot's expiration enters the counter-lung which accommodates the pilot's tidal volume during breathing to maintain the loop at constant pressure during the breathing cycle. Inhalation oxygen is drawn from the circulating loop through a heat exchanger used as a dehumidifier. This is required because the flow in the circulating loop will be about $120^{\circ} \mathrm{F}$ and nearly saturated with water vapor. A separator downstream of the dehumidifier removes the condensed 


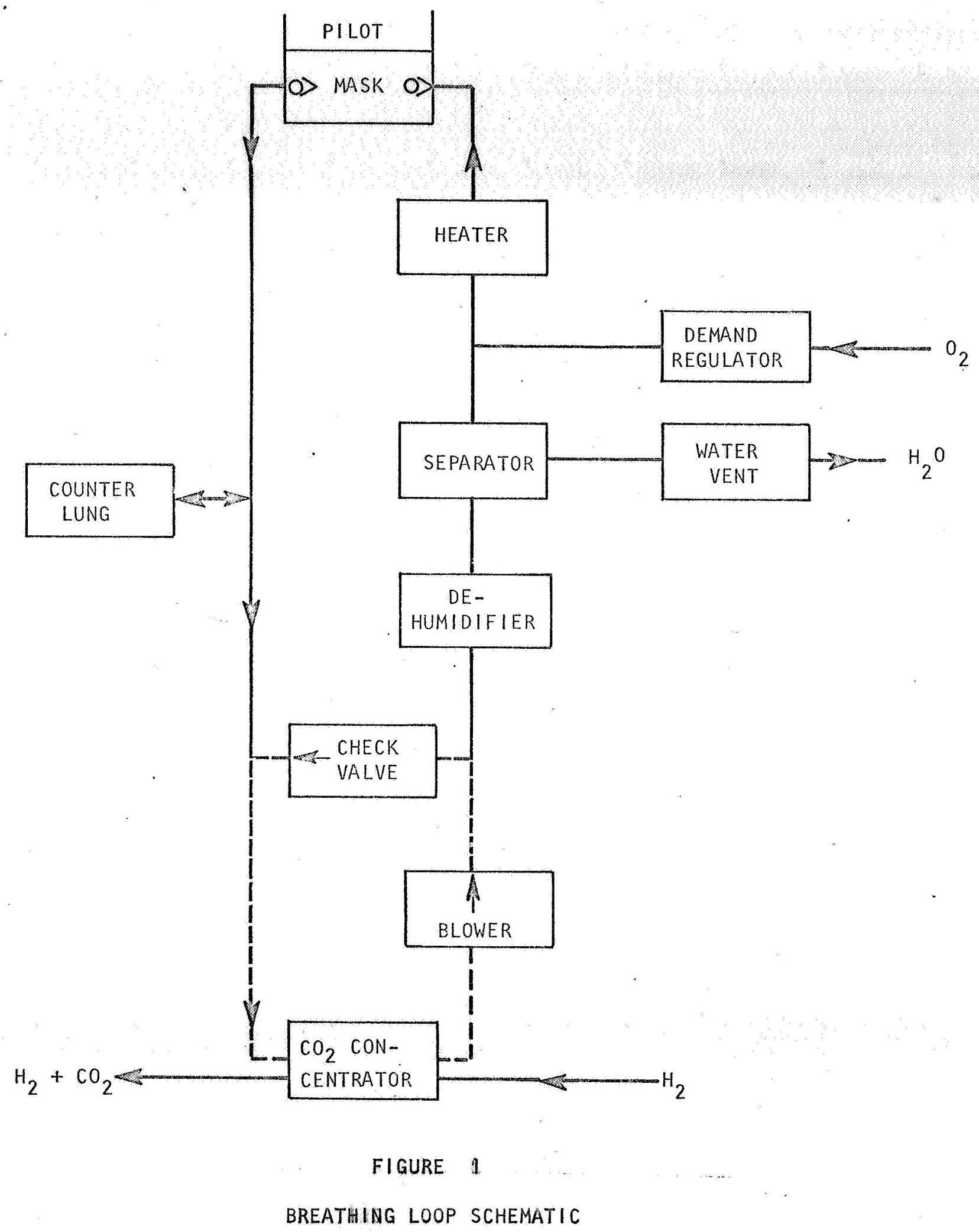


water and directs it to a water vent which vents the water from the breathing loop. Oxygen from the electrolysis cell enters through the demand regulator to make up the oxygen consumed by the pilot, the carbon dioxide concentrator, and system venting. Next, the oxygen is heated to a comfortable level for breathing by the pilot. During inhalation, the counter-lung is collapsed allowing this gas to enter the circulating loop.

Check valves in the mask maintain the inspiration and expiration flows in the proper direction. The check valve in the recirculating loop prevents "short circuiting" in the breathing loop.

This system can provide pressure breathing, i.e., the breathing loop pressure can be above the cabin pressure. This is required at cabin altitudes above 38,000 feet. The pressure breathing control will maintain the breathing loop pressure constant at 3 psia at altitudes between 38,000 and 43,000 feet. Above 43,000 feet, loop pressure will remain at eighteen inches of water above ambient pressure. At cabin altitudes above 43,000 feet, pressure suits are required. Pressure breathing is accomplished by using air to pressurize the outside of the breathing bag in the counter-lung. This pressure is regulated by an aneroid device similar to those employed in current pressure breathing demand oxygen regulators.

Denitrogenation is necessary to remove the nitrogen from the breathing loop. The nitrogen is eliminated from the body due to the partial pressure gradients existing while breathing pure oxygen. The NAOS system will accomplish this by continually venting a small portion of the pilot's exhaled gases. Another subsystem is shown in Figure 2. The electrolysis module requires a pressure balancing system for safe, reliable operation. Oxygen is supplied to the breathing loop, as required, by the demand regulator. The control of the 


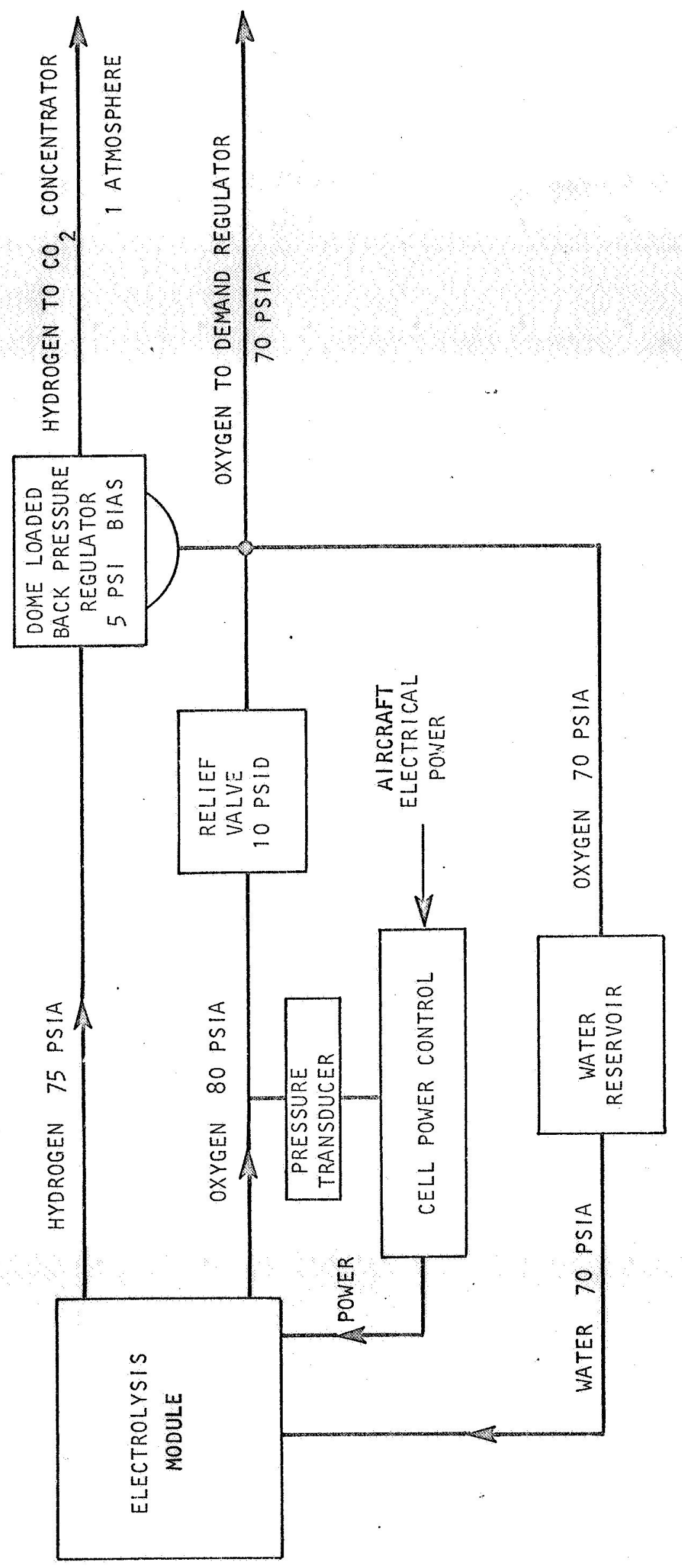

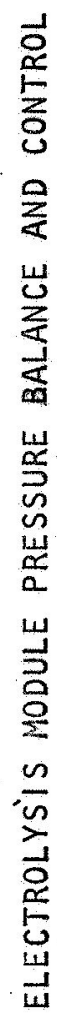


oxygen generation rate is accomplished by varying the electrical power to the electrolysis cell. The cell power control will adjust the electrical power to the electrolysis cell to maintain a constant oxygen pressure as monitored by a pressure transducer.

A relief valve in the oxygen line is used to drop the pressure level so that the water feed will be maintained at 10 psi below the oxygen pressure. The hydrogen pressure is maintained between these pressures by a dome-loaded back pressure regulator. All pressures, therefore, are referenced to the oxygen pressure which in turn is controlled by power to the cell.

SYSTEM ANALYSIS - A thermal analysis of the NAOS system was conducted to evaluate methods of maintaining a water balance in the carbon dioxide concentrator cell and to determine the influence of component variables on the system performance.

Cooling of the carbon dioxide concentrator by use of a separate heat exchanger in the circulating loop was not found to be practical due to the relatively low circulation flow compared to the sensible heat load. Also, it would be desirable to have nearly constant conditions of temperature and humidity in the circulating loop to avoid large temperature and water vapor pressure gradients in the carbon dioxide concentrator. A separate cooling system is, therefore, required.

The electrolysis cell can be cooled by evaporation of water from within the cell with the hydrogen and oxygen flows carrying off the water vapor. However, the electrolysis cell cooling by water evaporation would require either much higher operating temperatures or much lower pressures than presently specified. Operating the electrolysis cell at a pressure level of 80 psia is desirable in that it allows a larger mass of oxygen to be stored in the cell cavities and oxygen manifolds which results in less sensitivity to pulsating 
flow demands of the breathing loop and provides reserve oxygen for emergencies. Operating the cell at this pressure and expanding down to the breathing loop pressure results in a low dew point in the hydrogen and oxygen feed lines. This, in turn, was found to result in very little interaction between the electrolysis cell operation and other system components. The analysis showed that the electrolys is cell operating temperature may be selected independent of the carbon dioxide concentrator cell temperature. Variations in the electrolysis cell temperature will have very small effects on the carbon dioxide cell equilibrium electrolyte concentration. External forced convection cooling of the electrolysis cell was selected and analysis showed that the control of the cell temperature could be fairly coarse.

Analyses of heat and mass transfer within the electrolysis cell and carbon dioxide concentrator cell showed that the gas conditions leaving these cells would be in equilibrium with the cells. That is, the gas exits at the cell temperature and with the same water vapor pressure as the electrolyte.

A very important consideration in the system is the maintenance of a relatively constant electrolyte concentration in the carbon dioxide concentrator. The analysis indicated that the carbon dioxide concentrator cell water balance is self-regulating in that the electrolyte concentration will adjust to maintain a water balance. For example, if the cell starts to "dry out" the water vapor pressure in the cell decreases, allowing less water to be carried away in the gas stream. The cell temperature, however, must be controlled quite closely because the equilibrium electrolyte concentration is sensitive to small changes in the cell temperature.

It was also found that if the oxygen consumption by the pilot is proportional to his respiratory minute volume then the electrolyte concentration in 
the carbon dioxide concentrator will be independent of the respiratory flow rate. The circulating loop flow rate also has no effect on the water balance. The effects of altitude, or system pressure level, on the system performance was examined. It was found that the carbon dioxide concentrator electrolyte concentration will be less sensitive to rebreather loop pressure if the pressure in the anode gas compartment of the cell is maintained constant. Thus, this requires an absolute back pressure regulator in the hydrogen-carbon dioxide line downstream of the carbon dioxide concentrator.

SYSTEM INTEGRATION - After completing the initial design of the system to meet the design criteria previously discussed and evaluating the results of the system analyses, a complete system design. was performed. This involved selecting and interconnecting components in the system to achieve the desired performance. Figure 3 is a pictorial schematic of the system. This schematic shows the principal components as well as the related accessories. Heat rejection from the electrolysis cell, carbon dioxide concentrator and dehumidifier will be accomplished by gas or liquid cooling systems aboard the aircraft. Temperatures will be controlled by regulating the coolant flow through these components. The temperature controls, instrumentation for performance monitoring, and warning alarms for safety are part of the system but are omitted from the schematic for clarity.

Looking ahead to a prototype flight system, certain safety features and indicators could be used to protect the aviator and to inform him of malfunctions including:

1. $\mathrm{O}_{2}$ partial pressure for hypoxia warning

2. $\mathrm{CO}_{2}$ partial pressure for hypercapnia warning

3. High component temperatures 


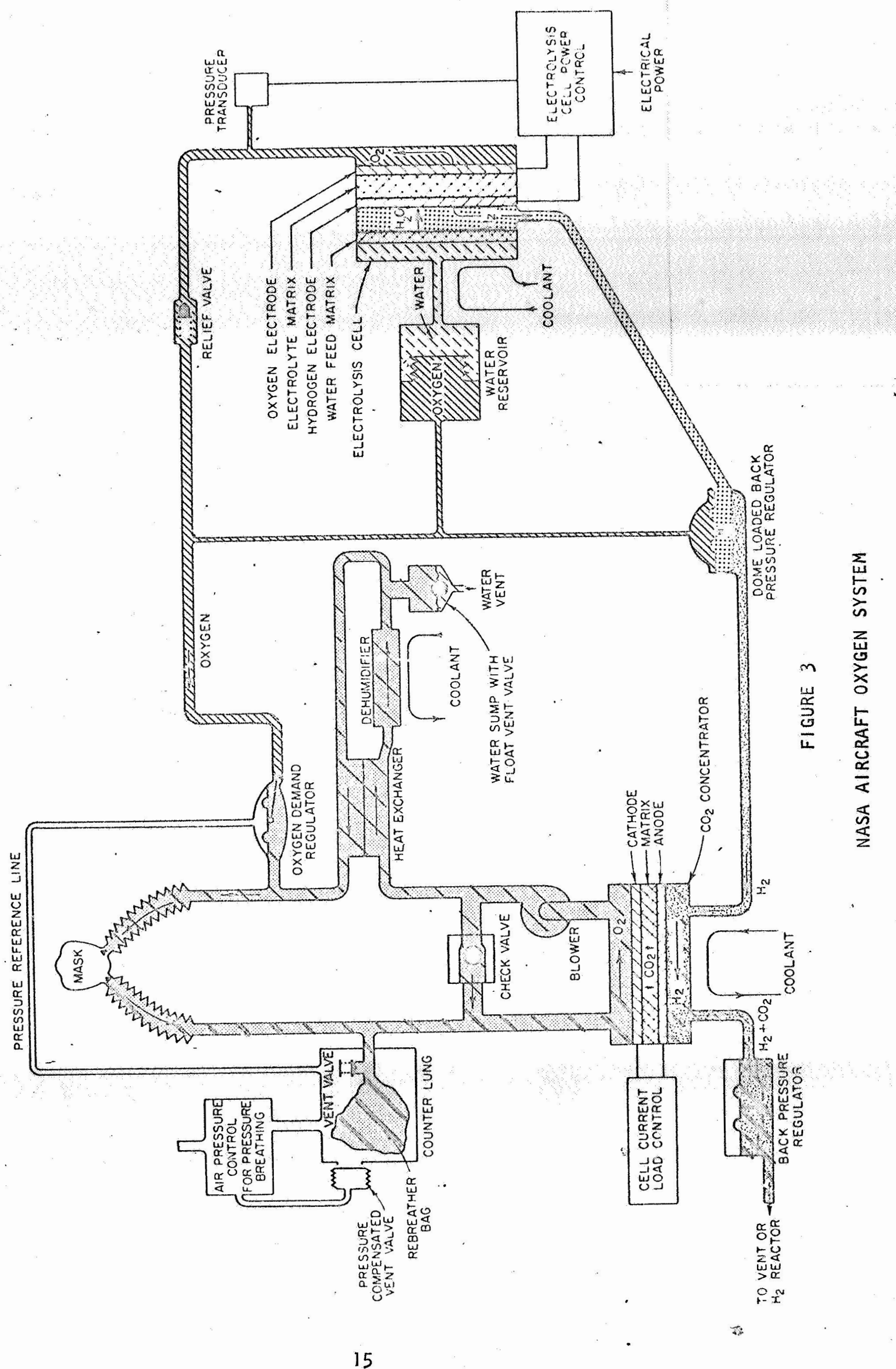


4. Cell voltage change

5. Water storage reserve

6. Low oxygen supply pressure

The hypoxia warning device would measure oxygen partial pressure in the mask and warn the aviator if it is below a safe level. This would be due to air leakage into the system or failure of the nitrogen vent valve. A high carbon dioxide partial pressure would warn the pilot that emergency action is required. Both of these occurrences would actuate an automatic oxygen purge of the system. High component temperature would indicate that the cooling system or the component itself is failing. A significant change in a carbon dioxide concentrator voltage or electrolysis module cell voltage would be indicative of a problem. It may be desirable to incorporate a switch to electrically bypass a cell which has an abnormal voltage. The water reserve in the electrolysis module water feed tank could be indicated by converting the electrolysis module ampere-hours directly into water consumed. Also, a microswitch in the water reservoir could be tripped at a predetermined travel of the diaphragm to warn of a minimum reserve.

A pressure switch in the oxygen supply line would warn of a low level of oxygen in the generating network. This also could be used to activate an emergency oxygen supply.

These and other safety features for a prototype NAOS system can be considered and evaluated better in the later phases of the program after more experience is gained and firmer requirements are established.

PROJECTED PROTOTYPE SYSTEM SIZE AND WEIGHT - An estimate was made of the size and weight of the NAOS components for a fully-developed prototype. These are shown in Table 4. The estimates are based on refined cell construction methods and materials. Auxiliary component information reflects present 
Projected Prototype System Size and Weight

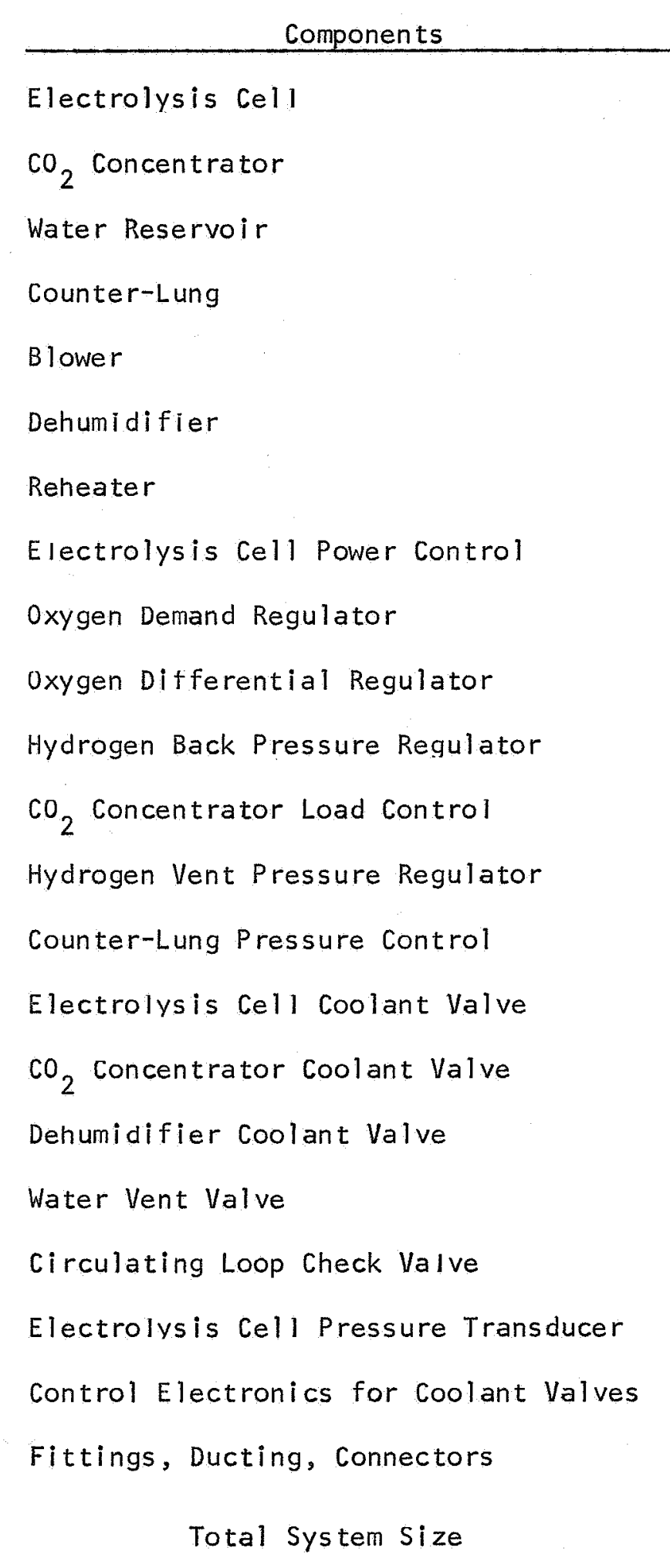

\begin{tabular}{|c|c|}
\hline $\begin{array}{l}\text { Flight Size, } \\
\text { Inches }\end{array}$ & $\begin{array}{l}\text { Flight Weight } \\
\text { Pounds } \\
\end{array}$ \\
\hline $3 \times 6 \times 8$ & 16 \\
\hline $8 \times 7 \times 2$ & 10 \\
\hline 4.1 dia $\times 5$ & 3.5 filled \\
\hline $5 \times 8.5 \times 3.5$ & 2 \\
\hline 3 dia $\times 3$ & 1.7 \\
\hline $1 \times 1 \times 5$ & 1 \\
\hline $1 \times 1 \times 3$ & .5 \\
\hline $5 \times 6 \times 4.5$ & 2.5 \\
\hline 2 dia $\times 1$ & .2 \\
\hline 2 dia $\times 1$ & .3 \\
\hline 2 dia $\times 1.5$ & .4 \\
\hline $4 \times 2.5 \times 2$ & 1.5 \\
\hline 2 dia $\times 1$ & .3 \\
\hline $3 \times 4 \times 2$ & .6 \\
\hline 1 dia $\times 2$ & .2 \\
\hline 1 dia $\times 2$ & .2 \\
\hline 1 dia $\times 2$ & .2 \\
\hline 1.5 dia $\times 2$ & .2 \\
\hline 1 dia $\times 0.5$ & .1 \\
\hline 1 dia $\times 1$ & .2 \\
\hline \multirow[t]{2}{*}{$3 \times 3 \times 4$} & 1.5 \\
\hline & 2.5 \\
\hline $5 \times 14 \times 14$ & 45.6 \\
\hline
\end{tabular}


technology, not necessarily in using existing components, but in manufacturing special purpose components. For example, a production unit would incorporate regulators with direct porting to other components rather than joining by using tubing and fittings. Components, therefore, require careful system integration considerations such that when combined into a system, the optimum size and weight system is obtained. This is not the same as combining optimum components. PROTOTYPE MOCK-UP - A mock-up of a prototype NAOS sys tem was fabricated to gain the packaging experience and to be aware of the packaging considerations early in the program. Since neither a package configuration nor size limitation had been established it was decided that a relatively flat, square package would be representative of an aircraft system which could, for example, be placed below an aviator's seat.

A significant effort was made to design the component interconnections of ducting, tubing and wiring for efficient use of space. Some of the component shapes were changed slightly for an improvement in package envelope. The counterlung and electronics package were examples where modification of the shape did not change its performance but did aid the package design.

An assumption was made that liquid coolant would be used to cool the electrolysis module, carbon dioxide concentrator and heat exchanger. This assumption allowed these components to be more compact since finned heat transfer surface was not required as with an air cooling method.

Once the package design was completed, the major components were fabricated of plastic. Several of the components such as regulators, valves and fittings were actual production pieces without internal parts. Figure 4 shows the completed prototype mock-up with the principal components labeled. Figure 5 shows the model with connections to the mask. This mock-up represents the results of 


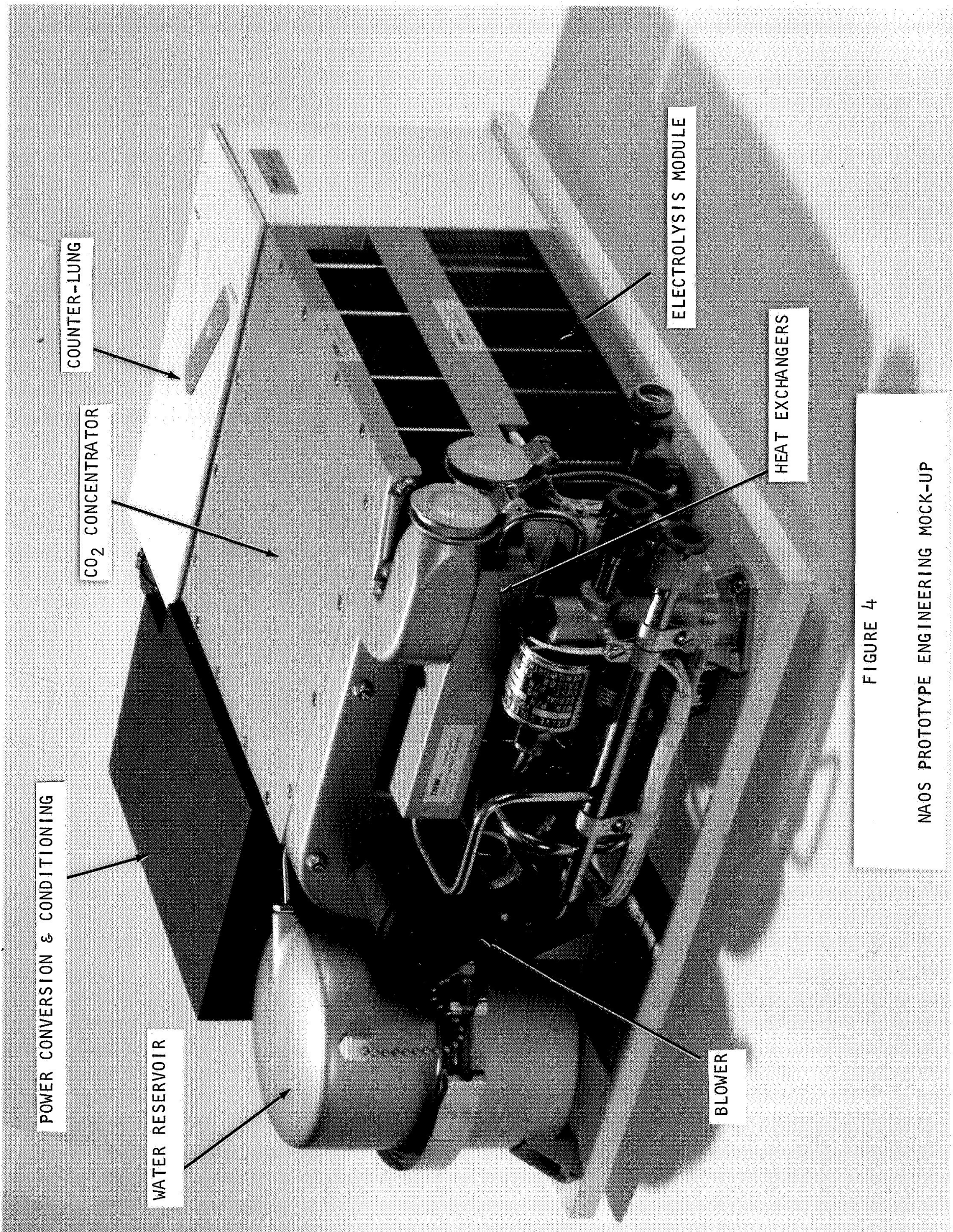




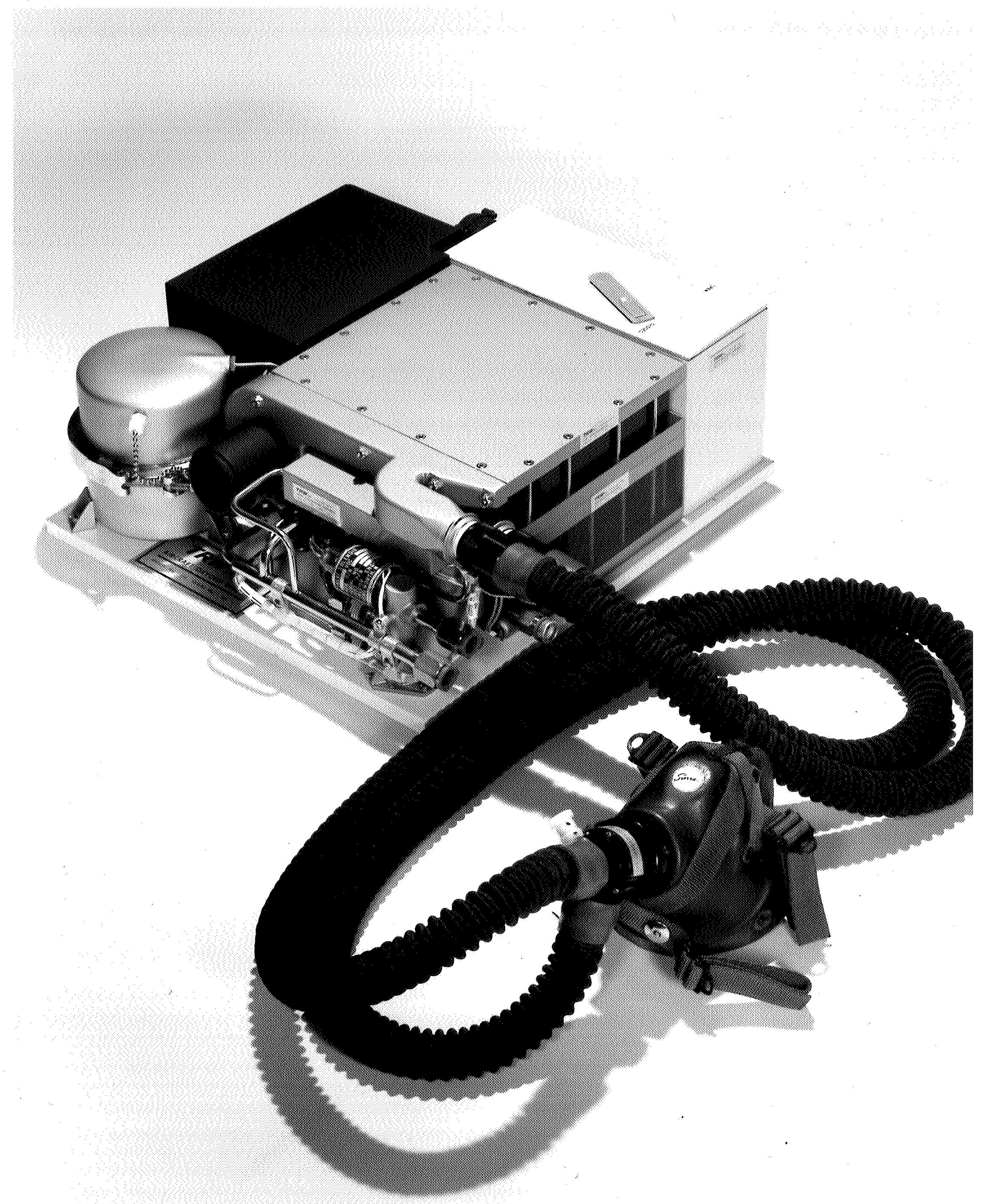

FIGURE 5

NAOS MOCK-UP WITH BREATHING MASK 
a detailed design effort in which all components are felt to be realistic in size and configuration. All electrical and plumbing connections are accounted for. It is felt that this mock-up represents an attainable configuration based on the projected efforts in the three phases of the NAOS program. SPACECRAFT APPLICATION

The spacecraft cabin is merely an extension of the rebreather loop volume to include the complete spacecraft cabin requiring oxygen generation and removal of carbon dioxide from that atmosphere. Part of the rebreather system, such as the nitrogen vent valve (see Figure 3), has only limited system application such as the aircraft oxygen system; but the other system components could be used in spacecraft environmental control systems. With the completion of the development work performed under the program, the components may prove to be competitive wi th "state-of-the-art" regenerable systems currently being considered for spacecraft application.

Various carbon dioxide removal systems (silica gel-molecular sieve systems, metal oxide systems and solid amine salt systems) are currently being investigated for possible spacecraft usage. Each system has its own inherent limitations (such as high energy requirements, low capacity, poor reliability and/or high weight penalty) and could be replaced by the carbon dioxide concentrator. The carbon dioxide concentrator should be a reliable, low weight, low power system that will prove to be competitive with the other carbon dioxide management systems.

With the significance of maintainability becoming increasingly apparent, it should be noted that the electrochemical carbon dioxide concentrator requires few components. Additionally, the major cell hardware components lend themselves to modularization and ease of replacement. 
Various types of electrolys is cells (1 iquid and vapor feed, acidic and basic electrolyte, liquid and solid electrolyte) are currently being tested for possible spacecraft usage (7). The static-feed water electrolysis cell used in the aircraft oxygen system could prove to be competitive with these other electrolys is cells and be used in a spacecraft environmental control system.

An excellent demonstration of the applicability of the carbon dioxide concentrator and the electrolysis cell to integrated spacecraft carbon dioxide removal and oxygen recovery systems is shown in the general system schematic of Figure 6. In this system, the two referenced components are integrated with a Bosch carbon dioxide reduction reactor. There are no inherent materials balance problems in this system and such an integrated system should have minimal operational difficulties.

OTHER APPLICATIONS

Another application is the submarine (submerged shelters such as the Sealab are included in this category). Currently, the atomic submarine fleet uses monoethanolamine (MEA) carbon dioxide scrubbers and high pressure electrolysis systems to produce oxygen. Hydrogen and carbon dioxide are vented overboard.

The carbon dioxide concentrator of the aircraft oxygen system appears to be an attractive substitute for the MEA scrubber. The required hydrogen for the concentrator is already available from the electrolysis cell and the advantages should be numerous: 1) better reliability, 2) lower power consumption, 3) no organic volatility or toxicity problems, and 4) good chemical stability of the electrolyte (MEA is not stable). 


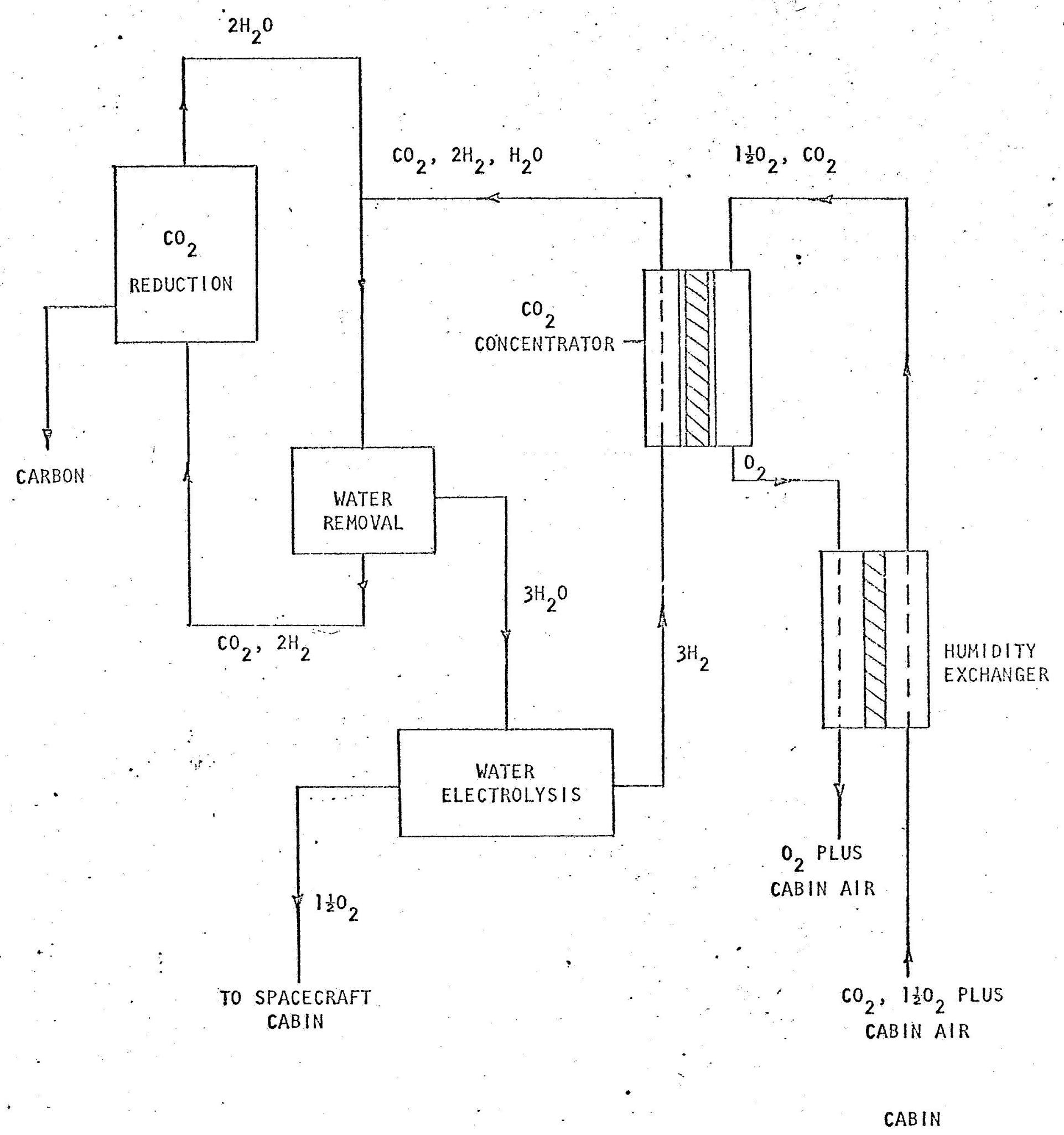

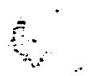

FIGURE 6

SPACECRAFT OXYGEN RECOVERY SYSTEM 
REFERENCES

1. A. J. Adduci, "Comparison Study of Liquid Oxygen (LOX) Supply System to an Electrochemical 0xygen Supply System," AFFDL-TR-66-193, January 1967.

2. R. A. Wynveen, "A Logistics Independent Oxygen System for Military Aircraft," AlAA Paper No. 66-787 presented at AlAA Military Aircraft Systems Meeting, Dallas, Texas, October 1966.

3. A. D. Babinsky and G. L. Mrava, "The Experimental Evaluation of An Oxygen Rebreather Loop," presented at the Fifth National Flight Safety, Survival and Personal Equipment Symposium, San Diego, California, September 1967.

4. G. L. Mrava and R. A. Wynveen, "Aircraft Oxygen Systems - The Next Generation," Aerospace Medical Association Meeting, April 1967.

5. Military Specification MIL-1-9475A (USAF), "Installation Design of Liquid 0xygen Systems in Aircraft, General Specifications For," July 10, 1959.

6. A. D. Babinsky, D. L. DeRespiris and S. J. Derezinski, "Carbon Dioxide Concentration System," NASA CR 72086, July 30, 1966.

7. T. Wydeven and R. W. Johnson, "Water Electrolysis: Prospect for the Future," presented at the American Society of Mechanical Engineers Aviation and Space Division Conference, Beverly Hills, California, June 1968. 


\section{FI GURES}

\begin{tabular}{ll}
$\begin{array}{c}\text { Figure } \\
\text { No. }\end{array}$ & Breathing Loop Schematic \\
\hline 1 & Electrolysis Module Pressure Balance and Control \\
2 & NASA Aircraft Oxygen System \\
3 & NAOS Prototype Engineering Mock-Up \\
4 & NAOS Mock-Up with Breathing Mask \\
5 & Spacecraft Oxygen Recovery System
\end{tabular}

